\title{
Tuottavuuden kehitys nurmisäilörehun tuotannossa
}

\author{
Timo Sipiläinen ja Matti Ryhänen \\ Helsingin yliopisto, Taloustieteen laitos, PL 27, 00014 Helsingin yliopisto \\ etunimi.sukunimi@helsinki.fi
}

\section{Johdanto}

Rehujen hintasuhteet muuttuivat merkittävästi Suomen liityttyä Euroopan unioniin. Tällöin tilalla tuotetun karkearehun yksikkökustannus ja markkinoilta ostettavan rehuviljan hinta muuttuivat ostoviljaa suosivaksi. Jos kotoisten karkearehujen yksikkökustannusta ei kyetä alentamaan ostorehun hinnan tasolle, ostorehu korvaa yhä suuremmassa määrin kotoista karkearehua maidontuotannossa ja erityisesti sitä laajennettaessa. Koska tuotantopanosten hintataso ja hintasuhteet määräytyvät tilan ulkopuolella, yksikkökustannusten mahdollinen aleneminen on perustettava suurelta osin teknisen kehityksen myötä tapahtuvaan tuottavuuden parantamiseen ja mahdollisen tehottomuuden poistamiseen. Tehokas tuotanto käyttää vähemmän panoksia tuotettua yksikköä kohti kuin tehoton tuotanto. Tuotannon tehokkuus ei kuitenkaan takaa tuotannon kannattavuutta.

Teknisen tehokkuuden/tehottomuuden mittaamisen lähtökohtana on, että kaikki yritykset eivät toimi tehokkaasti, vaan syystä tai toisesta epäonnistuvat teknisesti parhaan mahdollisen panos-tuotossuhteen saavuttamisessa. Koska ideaalipisteiden löytäminen on vaikeaa jollei mahdotonta, tehokkuustarkastelu perustuu yrityksen vertaamiseen muihin vastaaviin yrityksiin (etsitään parhaan käytännön mukaista rajapintaa).

Tuottavuudella tarkoitetaan tuotoksen suhdetta tuotannossa käytettyyn panokseen. Usein tuotettavia tuotteita on useita samoin kuin käytettäviä panoksia. Siten kokonaistuottavuuden laskemiseksi tuotokset ja panokset on aggregoitava, jotta em. suhde ja erityisesti sen muutos ajan myötä voidaan laskea. Tuottavuuden muutos voidaan määrittää indeksilukujen avulla, ekonometrisesti tai matemaattisen ohjelmoinnin keinoin.

Tässä tutkimuksessa tarkastellaan, millaisia ovat olleet tuottavuuden ja tehokkuuden muutokset säilörehuntuotannossa 1990-luvulla. Samalla selvitetään, onko toimintaympäristön muutoksilla ollut yhteyttä säilörehuntuotannossa tapahtuneisiin muutoksiin.

\section{Aineisto ja menetelmät}

Tutkimusaineistona on Maaseutukeskusten Liiton hintalaskelma-aineistot (Hila) vuosilta 1990 - 2000. Tutkimuksen kohteeksi valittiin kaikki 138 tilaa, jotka olivat mukana aineistossa kaikkina vuosina muodostaen täydellisen paneeliaineiston. Kustannuserät muunnettiin vuoden 1998 hintatasoon Hilalaskelman kustannuseriä vastaavien Tilastokeskuksen julkaisemien panoshintaindeksien perusteella. Työkustannus ja muut muuttuvat kustannukset kuitenkin muunnettiin MKL:n Hila-laskelmien normihintojen muutoksen mukaisesti. Tutkimuksessa käytettiin yhtä tilakohtaista tuotosta (säilörehusato rehuyksiköinä) ja neljää panosta: lannoitekustannusta, muiden muuttuvien kustannusten ja työkustannuksen summaa, kone- ja rakennuskustannusta mukaan lukien rehun siirtonormi sekä säilörehualaa hehtaareina.

Tehokkuuden ja tuottavuuden mittaaminen kytkeytyvät toisiinsa Malmquist-indeksissä ${ }^{\square}$ (Färe ym. 1994). Siinä tuottavuuden muutos määritetään etäisyysfunktioiden avulla. Jos teknistä tehottomuutta esiintyy, Malmquist tuottavuusindeksi voidaan jaotella kahteen osaan. Ensimmäinen, kaavan 1 sulkujen ulkopuolinen osa kuvaa tehokkuusrintaman saavuttamista eli muutosta teknisessä tehokkuudessa. Toinen, suluissa oleva osa ilmaisee muutosta teknologiassa. Se mittaa muutosta etäisyysfunktioiden geometrisena keskiarvona laskettuna suhteessa havaintoihin periodilta $t \mathrm{ja}$ periodilta $t+1$. Näin tekninen muutos on määritetty muutokseksi maksimituottavuudessa ajan yli.

$M_{i}\left(y^{t}, y^{t+1}, x^{t}, x^{t+1}\right)=\frac{D_{i}^{t+1}\left(y^{t+1}, x^{t+1} \mid C R S\right)}{D_{i}^{t}\left(y^{t}, x^{t} \mid C R S\right)}\left[\frac{D_{i}^{t}\left(y^{t+1}, x^{t+1} \mid C R S\right)}{D_{i}^{t+1}\left(y^{t+1}, x^{t+1} \mid C R S\right)} \frac{D_{i}^{t}\left(y^{t}, x^{t} \mid C R S\right)}{D_{i}^{t+1}\left(y^{t}, x^{t} \mid C R S\right)}\right]^{1 / 2}$

\footnotetext{
${ }^{1}$ Malmquist (1953) kehitti panosetäisyysfunktioihin perustuvan indeksin, joka tuotantoanalyysissa vastaa panosmääräindeksiä. Shephard (1970) esitteli vastaavan tuotosetäisyysfunktioihin perustuvan tuotosmäääindeksin. Caves ym. (1982) määrittelivät tuottavuusindeksin, joka ilmaistaan joko panos- tai tuotosetäisyysfunktioiden avulla. Tämä indeksi ei sisältänyt teknisen tehottomuuden mahdollisuutta.
} 
Tehokkuuden muutos voidaan jakaa puhtaan teknisen tehokkuuden muutokseksi ja skaalatehokkuuden muutokseksi (Färe ym. 1994). Tekninen muutos voidaan puolestaan jakaa panos- ja tuotosharhaiseen sekä teknisen muutoksen suuruuskomponenttiin (Färe ym. 1996). Jos tuotoksia on ainoastaan yksi, tekninen muutos voidaan ilmaista ainoastaan panosharhaisen ja suuruuskomponentin tulona. Edellä mainittujen suureiden laskemiseen tarvittavat etäisyysfunktiot määritettiin lineaarisilla ohjelmointimalleilla OnFront 2.01 ohjelmistoa käyttäen. Etäisyysfunktioiden määritys perustui DEAmenetelmään (data envelopment analysis).

Tuottavuuden ja tehokkuuden muutosta tarkasteltiin myös stokastisilla SFA-rintamamalleilla (stochastic frontier analysis). Ne voidaan laatia siten, että tuottavuuden muutos on jaettavissa tekniseen muutokseen ja tehokkuuden muutokseen. Deterministisistä DEA-malleista poiketen SFA-malliin liitetään stokastinen virhetermi, johon ainakin osa mittausvirheistä päätyy. SFA-mallin lähtökohtana käytettiin seuraavaa ekonometrista translog-funktiomäärittelyä (Battese ja Coelli 1992)

$$
\begin{gathered}
\ln \mathrm{y}_{\mathrm{it}}=\beta_{0}+\sum_{\mathrm{j}=1}^{\mathrm{h}} \beta_{\mathrm{j}} \ln \mathrm{x}_{\mathrm{jit}}+\beta_{\mathrm{t}} \mathrm{t}+1 / 2 \sum_{\mathrm{j}=1}^{\mathrm{h}} \sum_{\mathrm{k}=1}^{\mathrm{h}} \beta_{\mathrm{jk}} \ln \mathrm{x}_{\mathrm{jit}} \ln \mathrm{x}_{\mathrm{kit}}+\beta_{\mathrm{tt}} \mathrm{t}^{2} \\
+\sum_{j=1}^{h} \beta_{j t} \ln x_{j i t} t-u_{i t}+v_{i t}
\end{gathered}
$$

missä $y_{i t}$ on i:nnen maatilan tuotos vuonna $t, x_{j i t}\left(x_{k i t}\right)$ on saman maatilan i käyttämä panos $j(k)$ vuonna $\mathrm{t}$ (h panosta), $\mathrm{t}$ on aikatrendi, joka kuvaa teknistä muutosta, $\beta: \mathrm{t}$ ovat estimoitavia parametreja $\left(\beta_{\mathrm{jk}}=\right.$ $\left.\beta_{\mathrm{kj}}\right), v_{\mathrm{it}}$ oletetaan riippumattomaksi ja identtisesti normaalisti jakautuneeksi virhetermiksi, jonka keskiarvo on nolla ja varianssi on vakio ja $\mathrm{u}_{\mathrm{it}}$ kuvaa kunkin maatilan poikkeamaa teknisesti tehokkaasta rintamasta. $u_{i t}$ voi olla tilalle sama vuodesta toiseen tai tehokkuuden asteen annetaan muuttua ajassa seuraavasti:

$u_{i t}=u_{i} \eta(t)=\{\exp [-\eta(t-T)]\} u_{i}, \quad t \in \tau(i) ; i=1, \ldots, N$

jossa $\eta$ on estimoitava parametri ja $u_{i}$ noudattaa katkaistua normaalijakaumaa, jonka keskiarvo on $\mu$ ja varianssi vakio. Teknisen tehokkuuden arvo voi laskea, nousta tai pysyä ennallaan ajan myötä, mutta muutos on samanlainen kaikilla tiloilla. Lisäksi muutos on eksponentiaalinen. Malli ratkaistiin tietokoneohjelmalla Frontier 4.1 (Coelli 1996).

\section{Tulokset ja tulosten tarkastelu}

Tutkimustiloilla säilörehun viljelypinta-ala kasvoi yli kaksinkertaiseksi vuodesta 1990 vuoteen 2000 . Hehtaarisato oli poikkeuksellisen korkea vuonna 1990 ja 2000. Heikoimpina satovuosina erottuivat vuodet 1991, 1998 ja 1999. Viljelyalan kasvun myötä säilörehun tuotantokustannus hehtaaria kohti aleni reaalisesti erityisesti kone- ja rakennuskustannusten sekä lannoitekustannusten alenemisen vuoksi. Siten tuotannon intensiteetti hehtaaria kohti aleni. Tämän vuoksi heikkoinakin satovuosina $1998 \mathrm{ja}$ 1999 tuotantokustannus rehuyksikköä kohti oli reaalisesti alempi kuin hyvänä satovuonna 1990. Tilojen välillä oli merkittävästi hajontaa, eivätkä tilat ole kehittyneet samalla tavoin ajanjakson kuluessa.

Tilojen keskimääräinen teknisen tehokkuuden taso vaihteli vuosittain teknologiaoletusten ja tehokkuuden määritysmenetelmän mukaan. Parhaan panos-tuotossuhteen tilat tuottivat säilörehutuotoksen 30-40 prosenttia pienemmällä panosmäärällä kuin tilat keskimäärin. Peräkkäisten vuosien väliset tehokkuuslukujen järjestyskorrelaatiot olivat yleensä yli 0.5 ja korrelaatiot yleensä alenivat, kun mittausten välinen aika piteni. Kolmen vuoden liukuvien keskiarvojen käyttö kohotti korrelaatiota.

Tuottavuuden muutos riippui tarkasteluperiodista, tutkittavasta tilajoukosta ja määritysmenetelmästä. Koko tarkasteluperiodilla DEA-pohjaisella Malmquist-tuottavuusindeksillä mitattu tuottavuus kasvoi. Kasvu oli alle prosentin vuodessa, kun tarkasteltiin periodia vuodesta 1990 (korkea keskisato) vuoteen 1998 (alhainen keskisato) ja noin 1.5 prosenttia vuodessa vuoteen 2000 (korkea keskisato) mennessä. Vuosien 1991 ja 1997 välillä keskimääräinen tuottavuuden nousu oli 3.5 prosenttia vuodessa. Tekninen muutos vaihteli aikavälistä riippuen hieman yli kahdesta yli kolmeen ja puoleen prosenttiin vuotta kohti. Tekninen tehokkuus aleni yleensä selvästi tutkimusaineistossa, mutta joillakin periodeilla tehokkuuden muutos oli lähes nolla. Jos tarkastellaan muutosta vuosien 1991 - 1999 liukuvien keskiarvojen pohjalta, tuottavuuden kasvu oli keskimäärin 1.8 prosenttia jakautuen yli prosentin tehokkuuden vuotuiseen alenemiseen ja yli kolmen prosentin vuotuiseen tekniseen muutokseen. Viljan ja säilörehun yhteistuotannossa tuottavuuden vuotuinen kasvu oli tarkasteluperiodilla noin puoli prosenttiyksikköä hitaampaa kuin pelkässä säilörehun tuotannossa. 
DEA-pohjaisen Malmquist-indeksin mukaan teknisen tehokkuuden yli prosentin vuotuinen aleneminen vuosina 1991 - 1999 (liukuvat keskiarvot) jakautui koko tarkasteluajanjaksolla puolittain skaalatehokkuuden ja puhtaan teknisen tehokkuuden alenemiseen. Kuten teknisen tehokkuuden muutos, myös skaalatehokkuuden ja puhtaan teknisen tehokkuuden muutos vaihtelivat vuodesta toiseen. Panosharhaisuuden osuus teknisestä muutoksesta oli vuodesta 1991 vuoteen 1999 keskimäärin 0.6 prosenttia/vuosi ja suuruuskomponentin osuus 2.5 prosenttia/vuosi. Panosharhaisuus oli suurimmillaan 1990-luvun alussa ja jälleen EU-jäsenyyden alussa vuosina 1995-1996.

SFA-mallilla aineiston keskiarvopisteessä tekninen muutos oli 2.5 prosenttia vuodessa. Jos otetaan huomioon, että tekninen tehokkuus aleni mallin mukaan (vaikkakaan ei merkitsevästi nollasta poikkeavasti) keskimäärin prosentin vuodessa, tuottavuuden vuotuiseksi muutokseksi keskiarvopisteessä laskettuna tuli 1.5 prosenttia. Muutokset olivat samaa suuruusluokkaa kuin DEA-pohjaisella Malmquist-indeksillä lasketut, liukuviin keskiarvoihin perustuneet tulokset. Ennen EU-jäsenyyttä ja jäsenyysajalle estimoitujen SFA-mallien mukaan tekninen muutos oli molemmilla periodeilla samansuuruinen. Tiloille yhteistä ja yleistä teknisen tehokkuuden muutosta ei esiintynyt.

Tulosten mukaan tuotantoalue ja korjuuteknologia sekä nurmen osuus viljelyalasta vaikuttivat panos-tuotossuhteeseen. Tuotoksen jousto panosten käytön suhteen poikkesi korjuuteknologioittain useiden panosten osalta. Lisättäessä em. muuttujat malliin teknistä muutosta kuvaava kerroin pieneni, koska osa teknisestä muutoksesta tuli endogeeniseksi teknologiaan sen vaihtumista kuvaavan indikaattorin kautta. Samalla panosharhaista teknistä kehitystä kuvaavat regressiokertoimet menettivät merkitsevyytensä.

Tutkimusaineistossa tarkkuussilppurimenetelmää käyttävät tilat tuottivat säilörehun alhaisimmin yksikkökustannuksin ja pyöröpaalausmenetelmää käyttävien tilojen yksikkökustannukset olivat korkeimmat. Kun eri menetelmillä korjattavien rehujen hehtaarisadot, korjuualat ja säilörehun osuus peltoalasta olivat tiloilla samat, kustannukset olivat eri korjuuteknologioilla samalla tasolla.

\section{Johtopäätökset}

Tuottavuutta voidaan parantaa joko hyödyntämällä teknistä kehitystä tai parantamalla toiminnan tehokkuutta olemassa olevalla tekniikalla. Tutkituilla tiloilla tuottavuuden paraneminen säilörehuntuotannossa oli hidasta. Tuotannon tekninen tehokkuus näytti jopa hieman laskeneen. Koko tarkastelujaksolla liukuvien keskiarvojen pohjalta lasketun DEA-pohjaisen indeksin ja SFA-mallin tuottamat tulokset olivat samansuuntaiset. Tulokset olivat kuitenkin riippuvaisia mittausperiodista. Tuottavuuden osatekijät, tekninen tehokkuus ja tekninen muutos, näyttivät vaihtelevan vuodesta toiseen tuottavuutta enemmän. Satovaihtelut ja panosten voimakkaat hintamuutokset (deflatointi) vaikeuttivat tuottavuuden ja tehokkuuden muutosten luotettavaa määrittämistä 1990-luvulla.

Säilörehuntuotannon tuottavuus parani, kun hehtaarikohtainen panosten käyttö väheni. Samanaikaisesti säilörehun tilakohtainen viljelyala kasvoi. Koko tilan kasvintuotannon tuottavuus näytti kehittyneen säilörehuntuotantoa hitaammin. Tiloilla, joilla jokin tuotannonhaara kehittyy muita nopeammin, tämän tuotannonhaaran tuottavuus paranee yleensä taantuvia ja paikallaan pysyviä tuotannonhaaroja nopeammin.

DEA-pohjaisen Malmquist-indeksin mukaan tuottavuus parani tutkimusaineistossa nopeimmin jakson alun tehottomilla tiloilla. Usein tehottomuus ei kuitenkaan ole helposti poistettavissa. Maatalouden kasvintuotantoon liittyy useita tekijöitä, mm. tilan sijainti, sääsuhteet ja maalajit, joita viljelijä ei voi kontrolloida. Näiden vaikutusta tehokkuuseroihin ei voida poistaa viljelijän toimenpitein.

Tuotantoalue, säilörehun korjuumenetelmä ja nurmen osuus kokonaispeltoalasta vaikuttivat rintamatuotantofunktion muotoon. Tuotoksen taso vaihteli alueittain. Myös tuotantofunktion muoto poikkesi korjuutekniikoittain. Erot eivät kuitenkaan aiheudu pelkästään korjuutekniikasta, vaan valittu korjuutekniikka on osittain myös indikaattori muista tuotanto-olosuhteista. Pienillä lohkoilla ja pitkien etäisyyksien vallitessa pyöröpaalikorjuu voi olla ainoa ajateltavissa oleva vaihtoehto. Se voi osalla tiloista olla myös siirtymäkauden menetelmä, kun karjanhoidon jatkuvuus pitkällä aikavälillä on epävarmaa. Edellä mainituissa tapauksissa panostusta tuotantoon usein vähennetään. Tehottomuuden yksityiskohtaisten syiden määrittäminen ja niiden poistamismahdollisuuksien arviointi edellyttävät jatkotutkimuksia.

Tutkimustiloilla säilörehun yksikkökustannukset olivat alimmat tarkkuussilppurikorjuuta harjoittavilla tiloilla ja korkeimmat pyöröpaalausta käyttävillä tiloilla tuorerehukorjuun kustannusten sijoittuessa näiden välille. Kun otettiin huomioon eri korjuumenetelmiä soveltavien tilojen erot satotasossa, viljelylaajuudessa ja säilörehun osuudessa peltoalasta, korjuumenetelmien väliset erot yksikkökustannuksissa poistuivat. On myös huomattava, että pyöröpaalaukseen siirtyminen on tapahtunut 
laajasti aivan viime vuosina. Siten pyöröpaalausta käyttävien tilojen yksikkökustannuksia kohottaa suhteellisen uusi konekanta.

Hila-laskelmissa ilmoitetut sadot olivat nettosatoja. Sekä pyöröpaalatun että tuoreena korjatun säilörehun sadot olivat alemmat kuin tarkkuussilppurikorjatun rehun sadot. Satoeroon voivat olla syynä erot bruttosadoissa, jotka johtuvat viljelyolosuhteista tai tilan koko viljelymenetelmistä. Kirjallisuuden perusteella tuoreena korjatun ja tarkkuussilputun rehun korjuu- ja säilöntätappioiden pitäisi olla jokseenkin samansuuruiset (Zimmer ja Wilkins 1984 ref. McDonald ym. 1991; McGechan 1989). Kuitenkin satotasojen ero Hila-aineistossa näiden kahden korjuutavan välillä oli 15 prosentin luokkaa. Kirjallisuuden perusteella pyöröpaalatun säilörehun korjuu- ja säilöntätappiot ovat joitakin prosentteja suuremmat kuin kahdella edellä mainitulla korjuutavalla. Hila-aineistossa pyöröpaalatun rehun nettosato hehtaaria kohti oli kuitenkin ollut noin 20 prosenttia alempi kuin tarkkuussilppurikorjuuta harjoittavilla tiloilla. Erojen syiden tarkempi selvittäminen edellyttäisi tilakohtaisten lisätietojen keruuta. Esimerkiksi säilörehun määrän arvioinnin tarkkuuden parantamisen ohella rehun laadun vaihteluun tulisi kiinnittää huomiota.

Tuloksia tarkasteltaessa on huomattava, että yksikkökustannusten taso Hila-aineistossa on alempi kuin maatalouden kannattavuustutkimuksen kirjanpitoaineistossa muun muassa pääomakustannusten määrittämiserojen vuoksi (Riepponen 1998). Näin ollen myös säilörehun yksikkökustannuksen taso saattaa Hila-aineistossa olla suhteellisen alhainen. Kustannusten tason ja muutoksen määrittämistä vaikeutti myös epävarmuus laskelmissa käytettyjen Tilastokeskuksen panoshintaindeksien ja tutkimusaineiston nimellisten kustannussarjojen taustalla olevien hintojen yhteensopivuudesta. Sen vuoksi osa kustannussarjoista muunnettiin reaalisiksi käyttäen Hila-aineiston oletushintoja. Tästä huolimatta EU:iin liittymisen yhteydessä 1990-luvun puolivälissä erityisesti DEA-pohjaisten tuottavuusindeksien arvot vaihtelivat voimakkaasti. Osa vaihtelusta selittyy suurilla ja nopeilla hintamuutoksilla. Myös arvonlisäverotuskäytännön muutos 1990-luvun puolivälissä vaikeuttaa kone- ja rakennuskustannusten luotettavaa määrittämistä. Hila-aineistossa ne lasketaan kunakin vuonna käyttäen lähtökohtana jälleenhankinta-arvoja, joihin arvonlisäverotuskäytännön muutos vaikutti välittömästi.

Battese, G. \& Coelli, T. 1992. Frontier production functions, technical efficiency and panel data: with application to paddy farmers in India. Journal of Productivity Analysis. 3:153-169.

Caves, D.W., Christensen, L.R. \& Diewert, E.W. 1982. The economic theory of numbers and the measurement of input, output and productivity. Econometrica. 50:1393-1414.

Coelli, T. 1996. A guide to Frontier version 4.1: A computer program for frontier production function estimation. CEPA Working Paper 96/07, Department of Econometrics, University of New England, Armidale.

Färe, R. \& Grosskof, S. 1996. Intertemporal production frontiers: with dynamic DEA. 199 s. Kluwer Academic Publishers.

Färe, R., Grosskopf, S. \& Lovell, C.A.K. 1994. Production frontiers. 296 s. Cambridge University Press.

Malmquist, S. 1953. Index numbers and indifference surfaces. Trabajos de Estatistica. 4:209-242.

McDonald, P., Henderson, N. \& Heron, S. 1991. The biochemistry of silage. 340 s. Marlow.

McGechan, M., B. 1989. A review of losses arising during conservation of grass forage: part 1, field losses. Journal of Agricultural Engineering Research. 44: 1-21.

Riepponen, L. 1998. Maidon, viljan ja sianlihan tuotantokustannukset kirjanpitotiloilla. Teoksessa Ala-Mantila O. \& Riepponen L. Maatalouden tuotantokustannukset Suomessa. MTTL:n tutkimuksia n:o 222:94-120.

Shephard, R.W. 1970. Theory of cost and production functions. Princeton. Princeton University Press. 